Geografia e Ordenamento do Território, Revista Electrónica

Centro de Estudos de Geografia e Ordenamento do Território

http://cegot.org

ISSN :2182-1267

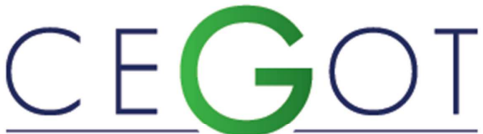

Centro de Estudos de Geografia e Ordenamento do Território
Alonso, Rosário

Universidad de Oviedo, Departamento de Derecho Público

Campus El Cristo-A, 33006 Oviedo (España)

mralonso@uniovi.es

\title{
Efectividad del derecho a la vivienda a través de los mecanismos de acceso al suelo en la legislación urbanística española
}

Referência: Alonso, Rosario (2015). Efectividad del derecho a la vivienda a través de los mecanismos de acceso al suelo en la legislación urbanística española. (GOT), n.o 7 (junho). Centro de Estudos de Geografia e Ordenamento do Território, p. 45-64, dx.doi.org/10.17127/got/2015.7.002

\section{Resumen}

Los poderes públicos están obligados a hacer efectivo el disfrute por todos los ciudadanos de una vivienda digna y adecuada. La mejor vía para garantizar la efectividad del derecho a obtener una vivienda, en condiciones de mercado que excluyan la especulación, es que tal responsabilidad se desarrolle por medio de adecuadas políticas públicas sociales, previo establecimiento de un marco organizativo y de programación, financieramente apoyado. Pero es igualmente claro también que garantizar la efectividad de este derecho precisa de mecanismos de acceso al suelo que estén articulados por medio de la legislación urbanística. A analizar algunas de las medidas que contiene la legislación urbanística española se dedica este trabajo.

Palabras clave: política de vivienda, vivienda social, urbanismo.

\section{Abstract}

The authorities are obliged to make the enjoyment of adequate housing a reality for all citizens. The best way to ensure the effectiveness of the right to obtain housing, on market conditions which exclude speculation, is that such responsibility is developed through social public policies, following the setting of a financially supported organizational and programming framework. But it is also clear that ensuring the effectiveness of this right 
needs some mechanisms for access to the land articulated by land law. This project's objective is to analyze some of the measures the Spanish land law contains.

Keywords: housing policy, social housing, town planning.

Resumo

As autoridades públicas são obrigadas a garantir que todos os cidadãos possam desfrutar de uma moradia digna e adequada. A melhor maneira de garantir a eficácia do direito à moradia, em condições de mercado que impede a especulação, é que tal responsabilidade é desenvolvido por meio de políticas sociais públicas adequadas, estabelecimento prévio de uma estrutura organizacional e de programação, apoiado financeiramente. Mas é igualmente claro também que, para garantir a realização desse direito são precisos mecanismos de acesso à terra que se articulam através de legislação planejamento. $\mathrm{Na}$ verdade, este trabalho é dedicado a analisar algumas das medidas contidas na legislação planejamento Espanhol.

Palavras-chave: política de habitação, habitação social, desenvolvimento urbano

\section{Efectividad del derecho a la vivienda en España: situación jurídica subjetiva y prestación social}

Más allá de que el derecho constitucional a la vivienda pueda estar articulado como un principio rector de las políticas públicas, se reivindique el valor normativo del precepto constitucional que lo consagra, o se afirme la existencia de un verdadero derecho subjetivo a la vivienda judicialmente exigible, como acontece en España, lo cierto es que el poder de exigir una determinada actuación a los poderes públicos para poder acceder a una vivienda solo alcanza a la exigibilidad de las prestaciones públicas establecidas en las normas jurídicas a través de las cuales se articulan las políticas de vivienda. En este sentido, se puede decir que el derecho al acceso a una vivienda, al menos en el ordenamiento jurídico español, es más bien un derecho en construcción, carecemos de un régimen jurídico básico que permita garantizar la efectividad general del derecho en todo el territorio del Estado.

En realidad, a lo que los poderes públicos están compelidos jurídicamente es a promover las condiciones necesarias para que todos los ciudadanos puedan disfrutar de una vivienda digna y adecuada; en definitiva, a hacer efectivo ese disfrute. Y la posibilidad de que los ciudadanos accedan realmente al disfrute de una vivienda para satisfacer sus necesidades 
va a depender, básicamente, de su capacidad económica, de sus niveles de renta, y del número de viviendas ofertadas en el mercado, en el mercado libre o en el mercado de viviendas sujetas a alguno de los regímenes de protección que el ordenamiento español regula. Se puede decir entonces que la configuración del derecho de acceso a la vivienda venía caminando en la legislación española, hasta el parón que ha representado la actual crisis económica y financiera, hacia su consolidación como prestación propia del Estado social $^{1}$, que ha de ser organizada y programada por los poderes públicos a través de políticas específicas de vivienda.

No fue así en el pasado. En un análisis histórico, las políticas públicas españolas de vivienda protegida han sido muy intervencionistas, pero escasamente sociales, no en vano a esta política se la ha denominado de "vivienda protegida" y no de "vivienda social". Nunca se ha articulado esta política como política social, ni ha centrado sus actuaciones en las familias y personas socialmente más marginadas. Por el contrario, la trayectoria de las sucesivas políticas de vivienda lo que ha hecho, más bien, es fomentar la construcción de viviendas como vía para promover el desarrollo económico general del país, prescindiendo de la problemática puntual de las necesidades de los más desfavorecidos. Las políticas de vivienda protegida se han desarrollado como una forma de promoción inmobiliaria, electiva y voluntaria para el promotor. Durante casi un siglo, todas ellas han sido fieles a un modelo claro que se ha mantenido bajo cualquiera que haya sido la forma de Estado y cariz de los gobiernos: el fomento público de construcción privada de vivienda de obra nueva en propiedad para una determinada clase social, las clases media y media-baja, que eran las que estaban en condiciones de poder llegar a adquirir la propiedad de las viviendas protegidas con apoyo público. Esto ha sido así tradicionalmente en España, aunque injusto sería no reconocer que los más recientes Planes Nacionales de Vivienda, los puestos en marcha para los períodos 2005-2008 y, sobre todo, 2009-2012, vinieron a contemplar otro tipo de ayudas públicas, como el alquiler, el alquiler con opción a compra, los alojamientos para colectivos más vulnerables, la rehabilitación, la renovación urbana, las reformas para incrementar la eficiencia energética de los edificios, etc. No debe llevarnos esto, sin embargo, a pensar que estuviéramos ante una configuración nueva de sus bases

\footnotetext{
${ }^{1}$ Como señala TEJEDOR BIELSA, J. "Régimen jurídico general de la vivienda protegida”, en LOPEZ RAMON, F. (Coord.) Construyendo el derecho a la vivienda, Editorial Marcial Pons, 2010, pág. 309 y ss.
} 
tradicionales. Sus bases siguen siendo las mismas, y esa es una de las razones que explican cómo hemos llegado a tener un mercado inmobiliario tan desequilibrado. En España, casi un siglo de políticas de vivienda protegida concebidas como forma de promoción inmobiliaria, junto con medidas de política urbanística liberalizadoras de suelo, y políticas tributarias que contemplaban la desgravación fiscal por compra de vivienda, conformaron un sector inmobiliario donde se han llegado a alcanzar en los picos más altos del ciclo económico alcista porcentajes de vivienda de nueva construcción de más del 80 por ciento, frente a tasas inferiores al 20 por ciento de rehabilitación, donde los porcentajes de vivienda en propiedad han llegado a superar el 85 por ciento, frente al 13 por ciento de vivienda en alquiler, porcentajes de vivienda libre del 89 por ciento, frente al 11 por ciento de vivienda social, más del 13 por ciento sobre el empleo total de empleo en la construcción, y más del 9 por ciento de la inversión del PIB procedente de la inversión residencial, con unos precios de la vivienda sobrevalorados, con carácter general, en más de un 30 por ciento.

Este desequilibrio ha sido una de las razones que explican el escenario de severa crisis económica en el que se ve envuelto el país, además de haber desencadenado un coste en términos sociales y medioambientales inasumible. Este, que sigue siendo al actual escenario, no permite que se den las condiciones de mercado para resolver satisfactoriamente las necesidades individuales de vivienda, ni en el mercado de vivienda libre, sin protección, que sigue siendo un mercado especulativo, con precios todavía sobrevalorados, ni en el mercado de vivienda sujeta a protección, que es un mercado injusto, porque los aspirantes a una de estas viviendas son más, en número, que las viviendas protegidas que se construyen, siendo por otro lado un mercado ficticio, porque el régimen jurídico de las viviendas protegidas, fundamentalmente por las limitaciones de uso y disposición de estas viviendas, que las alejan de poder revertir al mercado libre.

Por lo que llevamos dicho, es claro que la mejor vía para garantizar la efectividad del derecho a la vivienda, a obtener una vivienda en condiciones de mercado que excluyan la especulación, es su asunción por adecuadas políticas públicas sociales, previo establecimiento de un marco organizativo y de programación financieramente apoyado. Pero es igualmente claro también que garantizar la efectividad de este derecho precisa de mecanismos de acceso al suelo que estén articulados por medio de la legislación 
urbanística. Veamos a continuación qué medidas establece la legislación urbanística española para hacer efectivo este derecho.

\section{Mecanismos tradicionales de intervención en el mercado del suelo que posibilita la legislación urbanística: los patrimonios públicos de suelo}

El alto precio de la vivienda en España ha venido constituyendo demasiado tiempo un problema grave y generalizado. La vivienda se ha convertido así en un bien inaccesible para los que quieren acceder por primera vez a ella, para aquellos que quedan excluidos del mercado de vivienda libre, pero también para todos aquellos que no tienen resuelto su problema en el "mercado" de vivienda protegida. Es difícil señalar por dónde empezar ante el gran número de aspectos que deberían corregirse para que la vivienda dejara de suponer una carga financiera, económica y social tan pesada para los españoles. Rebajar significativamente la magnitud del problema precisa afrontar numerosas reformas estructurales de toda índole, incluyendo las referidas al sistema de financiación de los Ayuntamientos, las condiciones de competencia del sector de la construcción, la mayor transparencia fiscal de la vivienda, o la potenciación de la rehabilitación y la vivienda social. Algunas de estas medidas se habían empezado a tomar. Ciertamente, se ha producido una reacción, forzada por la crisis y el estallido de la burbuja inmobiliaria: así, por ejemplo, la desgravación fiscal de la compra de vivienda ha desaparecido y el fomento de la rehabilitación es ya una realidad que no admite vuelta atrás. Pero sobre todo, se está produciendo una reacción social, la sociedad española prioriza ya la consideración de la vivienda como un elemento fundamental para el funcionamiento y desarrollo de la propia sociedad, como instrumento fundamental para la emancipación de los jóvenes, y penaliza su consideración como un ámbito de inversión. Comienza a verse en la vivienda, en tanto que bien sujeto a propiedad, su función social, y éste sin duda es el fundamento de debates sociales hoy abiertos, como el sinsentido del inmenso stock de viviendas vacías mientras existan familias sin vivienda, la justificación de alquileres forzosos, o la expropiación o el gravamen fiscal a las viviendas desocupadas. 
No se puede decir que el legislador español no haya sido consciente de esta realidad, puesto que disponemos de una larga tradición normativa que ha venido predisponiendo instrumentos jurídicos al servicio de la intervención de la Administración Pública en la regulación del mercado inmobiliario. En efecto. Intentos normativos de intervención de la Administración para absorber las plusvalías generadas por la acción urbanística, y su configuración como una competencia pública, existieron ya en las primeras décadas del siglo pasado, donde la legislación de vivienda permitió desarrollar una verdadera política pública de adquisición de suelo para fomentar la construcción de viviendas por parte de los municipios a favor de las clases más desfavorecidas. La verdadera política pública de adquisición de suelo para intervenir en el mercado inmobiliario se ha desarrollado, en la tradición española, no en la legislación urbanística, como hubiera sido lo lógico, sino en la legislación estatal de vivienda, que vio con claridad que el suelo es el elemento principal de la política de vivienda ${ }^{2}$. De la misma manera, esta normativa permitió que el Estado se fuera convirtiendo, progresivamente, en promotor y urbanizador de grandes extensiones de terrenos, para proceder, posteriormente, a su enajenación. El objetivo que se pretendía por el legislador no va centrarse sólo en edificar grandes conjuntos de viviendas, sino luchar contra la especulación, cuestión que se convierte en el problema central del urbanismo del momento. Así, a partir de la década de los cuarenta se fue gestando una política de suelo en la que actuando por expropiación, ofertando así suelo urbanizado mediante sistemas de gestión pública a precios no especulativos, se pensaba que conllevaría una inmediata caída de la especulación.

\footnotetext{
${ }^{2}$ Así, en FONSECA FERRANDIS, F.E., El régimen jurídico de los patrimonios municipales del suelo, Instituto Pascual Madoz/BOE, Madrid, 1995, págs. 21 y ss. Hasta entonces, la intervención en este campo, para estimular y favorecer la construcción de "casas baratas", todo lo más llegaba hasta el reconocimiento de la facultad de las Administraciones de ceder gratuitamente terrenos de su propiedad, muy alejada de planteamientos plenamente urbanísticos. La normativa sobre vivienda que se desarrolla a partir del año 1921, tras afirmar que Estado, municipio y provincias, podían arrendar, vender, dar censo o ceder gratuitamente terrenos que fuesen adecuados para la construcción de casas baratas, concibió a los municipios como órganos de programación y gestión urbanística, encomendándoles no sólo el estudio y atención de las necesidades de vivienda en su territorio y formulación de proyectos de urbanización, sino la construcción de casas baratas en terrenos de su propiedad y la compra de terrenos necesarios para tal fin, mediante la expropiación de los solares o terrenos precisos. Fue desde entonces que la atención a las necesidades de viviendas para las clases más desfavorecidas se configuró como una obligación de los municipios. Además, a la atención de estas actividades quedaba afecto con carácter obligatorio un determinado porcentaje de los recursos municipales (al menos la mitad de los ingresos obtenidos por el impuesto de plusvalías y, voluntariamente, la mitad de los que obtengan por los arbitrios de carácter suntuario).
} 
La legislación estatal de vivienda fue el fundamento sobre el que se desarrolló la auténtica política urbanística de mediados del siglo pasado. Y cuando se aprueba la Ley del Suelo de 1956 y se intenta estructurar el conjunto del urbanismo, proporcionando incluso instrumentos para intervenir en el mercado del suelo, la normativa estatal sobre vivienda ya había adquirido por su propia dinámica una prepotencia absoluta. Esta circunstancia es la que permitió, y da explicación, al hecho de que siguiera desarrollando una política estatal de vivienda actuando al margen de los postulados de la Ley del Suelo, es decir, al margen del planeamiento urbanístico, al que claramente se marginó.

Esta evolución en la intervención pública en el mercado inmobiliario mostraba ciertamente un menosprecio de la Administración estatal hacia las posibilidades de la actuación municipal en este ámbito, llegando incluso a duplicar la filosofía propia de los "patrimonios municipales de suelo" que posibilitaba la legislación urbanística (adquisición masiva de suelo, urbanización en mano pública y dación al mercado, como medio que elimina la especulación y recupera las plusvalías), a través de la actuación encomendada a los organismos intermedios estatales que se fueron sucediendo: Gerencia de Urbanización, Instituto Nacional de la Vivienda, Instituto Nacional de Urbanización, Instituto para la Promoción Pública de la Vivienda, Sociedad Estatal para la Promoción de Suelo (SEPES).

La obtención de suelo para la acción urbanizadora a través de la expropiación no ha dado, sin embargo, el juego deseado, bien por las controversias surgidas en la aplicación de los criterios de valoración, bien por el retraso de la propia Administración en actuar. T.R. FERNÁNDEZ, señalando su ineficiencia, ha destacado cómo "la praxis había descalificado ya a la Administración, que expropiaba masivamente terrenos con el fin de devolverlos al mercado una vez urbanizados y regular así el mercado de solares y luego no cumplía o lo hacía con inusitado retraso la segunda parte de la operación. La delimitación de los polígonos a expropiar era, por otra parte, arbitraria en muchas ocasiones, lo cual, unido al fallo de las pretensiones reguladoras del mercado a las que respondía la expropiación de los mismos, contribuía a presentar socialmente la expropiación como una lotería a la inversa, ya que a quien se incluía en los polígonos correspondientes se le aplicaban los valores objetivos de la Ley, mientras que quienes quedaban al otro lado de la línea exterior de los mismos percibían en el mercado valores superiores a aquellos a resultas del libre (en cuanto no 
regulado) juego de la ley de la oferta y la demanda" ${ }^{3}$. Hasta tal punto fracasaron las expropiaciones máximas de suelo que SEPES, heredero del Instituto Nacional de Urbanización, hace tiempo que decidió abandonar ese instrumento y acudir al mercado para la adquisición de las parcelas en los polígonos en que posteriormente actuó.

Por su parte, la legislación urbanística dotó a la Administración municipal de la plena disponibilidad sobre un cierto volumen de suelo, con un doble fin de introducir en el mercado del suelo un factor de corrección de sus disfunciones, ofertando suelo urbanizado mediante sistemas de gestión pública a precios no especulativos, lo que se consigue bien a través de la configuración de la expropiación como sistema de actuación sistemática para la ejecución del planeamiento, bien mediante reservas de suelo para actuaciones urbanísticas completas de iniciativa pública, a través de la obligación de constituir "patrimonios municipales de suelo".

En la práctica, sin embargo, nuestras Administraciones han carecido de una política pública coherente de adquisición de suelo que permitiese la consecución de los objetivos legales, objetivos que, dicho sea de paso, no han estado dirigidos a la satisfacción del derecho de acceso de todos los ciudadanos a una vivienda digna y a precio razonable, sino, exclusivamente, a la adquisición masiva de suelo, su urbanización en mano pública y la dación al mercado como medio que elimina la especulación y permite recuperar las plusvalías. Hasta la segunda gran reforma de la Ley del Suelo en 1990, ésta ha sido la única finalidad de los patrimonios públicos de suelo en la legislación urbanística. Así, muy gráficamente, el artículo 89.2 del Texto Refundido de la Ley sobre Régimen del Suelo y Ordenación Urbana de 1976 establecía que dicho patrimonio "tendrá por finalidad prevenir, encauzar y desarrollar técnica y económicamente la expansión de las poblaciones, y se adscribirá a la gestión urbanística para inmediata preparación y enajenación de solares edificables y reserva de terrenos de futura urbanización", objetivo que sólo en parte alteró la Ley 8/1990, de 25 de julio, sobre reforma del Régimen Urbanístico y Valoraciones del Suelo, al vincular los terrenos integrantes de los patrimonios municipales del suelo bien a la construcción de vivienda de protección, bien a otras finalidades de interés social, pero sólo a partir del momento en que la Administración urbanística decidiera acerca de la efectiva

\footnotetext{
${ }^{3}$ Manual de Derecho Urbanístico, 1987, pág. 134.
} 
urbanización de los terrenos, no antes. Esta regulación se llevó posteriormente al art. 280.1 del Texto Refundido de la Ley sobre Régimen del Suelo y Ordenación Urbana de $1992^{4}$, y ha estado vigente hasta la entrada en vigor del Texto Refundido de la Ley de Suelo de 2008, que es la norma vigente.

Aun así, y a pesar que el Preámbulo de la Ley 8/1990 fue especialmente significativo respecto al trasfondo de la potenciación de los patrimonios públicos de suelo para incidir en la regulación del mercado inmobiliario o para adscribir superficies de suelo urbanizable a la construcción de viviendas de protección ${ }^{5}$, la redacción final del Texto Refundido de 1992 hizo que se mantuviera, en su artículo 276.1, la funcionalidad tradicional de los patrimonios de suelo, vinculada a la obtención de suelo para actuaciones urbanísticas completas de iniciativa pública ${ }^{6}$, introduciéndose, de esta manera, una doble vinculación hasta entonces desconocida, lo que sin duda ha jugado en contra de la clarificación de la naturaleza de los patrimonios públicos del suelo en tanto que instrumentos de intervención en el mercado inmobiliario, dificultando la consecución de sus objetivos. Esta duplicidad de fines sigue luciendo en los arts. 38.1 y 39.1 del Texto Refundido de la Ley de Suelo de 2008.

Mantenido así el modelo urbanístico que se introdujo en España en 1956, las reformas posteriores lo han seguido contemplado como un "proceso productivo" del que resultan determinados bienes que va a ser objeto de tráfico en el mercado inmobiliario ${ }^{7}$. En el contexto descrito, la legislación urbanística que han producido las Comunidades Autónomas

\footnotetext{
4 El precepto establecía, literalmente, que "Los bienes del Patrimonio Municipal del Suelo, una vez incorporados al proceso de urbanización y edificación, deberán ser destinados a la construcción de viviendas sujetas a algún régimen de protección pública o a otros usos de interés social, de acuerdo con el planeamiento urbanístico".

${ }^{5}$ Efectivamente, el citado Preámbulo señalaba, en su punto VII, que "Los restantes Títulos de la Ley tienen como propósito fundamental el de dar cobertura a una serie de instrumentos jurídicos cuya utilización por las Administraciones urbanísticas debe facilitar su gestión $y$, en particular, potenciar su intervención en la regulación del mercado del suelo [...] La potenciación de los patrimonios municipales de suelo no tiene alcance meramente cuantitativo, sino también cualitativo, en cuanto al destino que a los mismos ha de darse. En efecto, en el momento que se decida su urbanización, los terrenos integrados en estos patrimonios quedan vinculados primordialmente a la construcción de viviendas de protección oficial u otras finalidades de interés social, pues no seria justo ni coherente con el contenido del artículo 47 de la Constitución que las Entidades locales utilizasen los terrenos de su propiedad con miras puramente lucrativas, contribuyendo a incrementar las tensiones especulativas en vez de atenuarlas."

${ }^{6}$ Señalaba el art. 276.1 citado que "Los Ayuntamientos que dispongan de planeamiento general deberán constituir su respectivo Patrimonio Municipal del Suelo, con la finalidad de regular el mercado de los terrenos, obtener reservas de suelo para actuaciones de iniciativa pública y facilitar la ejecución del planeamiento."

7 Sobre ello, cfr. PAREJO ALFONSO, L., "La capacidad autonómica de establecimiento de una ordenación urbanística propia en el marco de la Ley 6/1998, de 13 de abril, de Régimen del Suelo y Valoraciones", Revista de Derecho Urbanístico, 166, 1998, págs. 11 y sigs.
} 
han revalidado la confianza en la operatividad de los cauces fundamentales que tradicionalmente han venido considerándose instrumentos reguladores del mercado del suelo por parte de las Administraciones, conteniendo una regulación detallada de los patrimonios municipales del suelo, el derecho de superficie, y los derechos de tanteo y retracto sobre terrenos o edificaciones y sobre viviendas sujetas a cualquiera de los regímenes de protección pública que nuestro ordenamiento contempla, al modo en que lo hizo en el pasado el Texto Refundido de la Ley del Suelo de 1992, y en una línea claramente continuista de la marcada por este texto estatal. Alguna Comunidad Autónoma, como es el caso de Castilla-La Mancha, llegó incluso a establecer que "los patrimonios públicos de suelo constituirán el medio principal para el desarrollo del servicio público de intervención en el mercado de suelo y de la política de vivienda", pudiendo gestionar dicho servicio en cualquiera de las formas permitidas por su legislación reguladora y la de contratación de las Administraciones públicas.

Unánimemente, la doctrina española ha destacado la ineficacia de estos mecanismos tradicionales, que no se han puesto al servicio de los objetivos para los que estaban legalmente configurados, sujetándolos, en el caso concreto de los patrimonios municipales de suelo, a una utilización perversa, basándose su gestión en fines puramente lucrativos ${ }^{8}$.

${ }^{8}$ Las razones que pueden dar explicación de la ineficacia de los patrimonios municipales de suelo son complejas y de muy variado orden. Por una parte, no puede desconocerse el incumplimiento que por parte de la inmensa mayoría de los Ayuntamientos se ha hecho de la obligación de consignar en sus presupuestos una cantidad equivalente al $5 \%$ del mismo para la formación e incremento de su patrimonio del suelo, incumplimiento que, paradójicamente, no ha determinado conflictividad judicial en España, a excepción de la Sentencia del Tribunal Supremo de 2 de noviembre de 2001 (Sec. 5a)), dictada en recurso de casación interpuesto contra la sentencia de la Sala de lo Contencioso-Administrativo del TSJ de Asturias sobre impugnación del Presupuesto General del Ayuntamiento de Oviedo, sentencia que se revoca, declarando disconforme a Derecho el acuerdo de aprobación del Presupuesto General Municipal para 1994, en cuanto que en dicho presupuesto no se reinvierte en conservación y ampliación del patrimonio municipal del suelo el importe de las enajenaciones que en él se prevén de terrenos de dicho patrimonio. Este es el único pronunciamiento judicial, al menos que conozcamos, que de esta cuestión existe. Por otro lado, de modo creciente "la Administración municipal ha sentido la tentación de convertirse en lo que se ha venido a llamar un operador inmobiliario más, financiando algunas de sus actividades con la obtención del mayor beneficio posible en el mercado del suelo y, por tanto, de entrar en connivencia con procesos alcistas de carácter especulativo" (SALANOVA ALCALDE, R., "Patrimonio públicos de suelo", en LÓPEZ RAMÓN, F. (Dir.), Estudio sistemático de la Ley Urbanística de Aragón, Cortes de Aragón, Zaragoza, 2003, pág. 329). Sobre esta cuestión vid. asimismo AGUINAGA MARTÍNEZ, M., "El patrimonio municipal del suelo como fuente de ingresos para los Ayuntamientos", Papeles de Economía Española, 92, 2002. Por lo que se refiere al derecho de superficie, las razones de su ineficacia son de un orden muy distinto. No derivan de una utilización perversa de la institución, sino precisamente de su falta de utilización, cuando se trata de una técnica que ofrece ventajas extraordinarias para obtener viviendas realmente asequibles a los grupos sociales menos favorecidos económicamente. Son razones de orden cultural o sociológico las que pueden dar explicación de esta situación, en un país que se 
De ahí que el que se haya llegado, aunque la situación no está generalizada, a la calificación de la actividad ligada a la constitución, mantenimiento y gestión de los patrimonios públicos del suelo como servicio público posee una relevancia singular en el plano teórico ${ }^{9}$. En este caso, la publicatio operada no tiene por objeto reservar la titularidad de la actividad a la Administración urbanística para que sea gestionada por ésta, directa o indirectamente, puesto que la "reserva", si queremos utilizar la expresión, o el carácter monopolístico y excluyente del servicio ya existe desde el momento en que la normativa urbanística impone la obligatoriedad de la constitución pública de patrimonios del suelo, siendo insusceptible dicha actividad, en esencia, de titularidad privada. Por el contrario, la trascendencia de la publicatio persigue controlar y asegurar la prestación de esa actividad, porque se entiende no ya que satisface un interés general, sino un interés social relevante, una necesidad pública que se ha considerado indispensable para sociedad.

Más allá de la revalidada confianza en los patrimonios públicos de suelo, y generalizada ya la posibilidad de constitución por las Comunidades Autónomas de su propio patrimonio -que prácticamente todas ellas contemplan- al objeto tanto de colaborar con los municipios en atención al cumplimiento de la funcionalidad del patrimonio municipal, vinculado ya claramente, como ya hemos visto, a la demanda de vivienda de protección, como de desarrollar los objetivos específicos derivados de la formulación de los instrumentos de planeamiento territorial, la legislación urbanística autonómica está agotando las posibilidades del marco estatal vigente, estableciendo, por ejemplo nuevas modalidades de derechos de tanteo urbanísticos, y articulando nuevos cauces directamente orientados a la articulación de una política de vivienda que garantice un coste equitativo para poder atender las necesidades de alojamiento del conjunto de la población, bien mediante el establecimiento de estándares y reservas de suelo vinculadas directamente a la

caracteriza por estar fuertemente arraigada en sus ciudadanos la aspiración de obtener el derecho de propiedad de la vivienda. En estas condiciones, se ha de reconocer que la mayor parte de quienes pretender disponer de vivienda a precios asequibles y a su alcance no se sentirán muy satisfechos al ser calificados de superficiarios y no de propietarios.

${ }^{9}$ Como es conocido, la noción de servicio público, a pesar de todos los debates a que se sujeta, mantiene un significado desde sus orígenes, que es "la reconducción de un sector de actividades socio-económicas a la órbita del poder público, con un marcado carácter instrumental, por cuanto, al margen del distinto régimen jurídico por el que se opte, lo que se pretende es imponer la obligatoriedad del servicio o actividad, y la regularidad y continuidad en la prestación, así como reafirmar los poderes de la Administración titular" (BERMEJO VERA, J. "Acción administrativa y potestades", en Derecho Administrativo. Parte especial, Civitas, 5a ed., pág. 67). 
construcción de vivienda protegida, bien mediante la formulación y desarrollo de programas urbanísticos de actuación que permitan garantizar en todo momento y coyuntura la viabilidad de las actuaciones más débiles del mercado, como es el caso de la vivienda protegida.

En cualquier caso, y a la vista de esta nueva normativa, lo que resulta evidente es que las Comunidades Autónomas, contemplan expresamente la promoción de suelo, pública y privada, orientada a la construcción de vivienda protegida como posible método eficaz para estabilizar el precio de los diversos segmentos del mercado inmobiliario y para cumplir el mandato constitucional de impedir la especulación del suelo.

\section{La afectación de usos del suelo a la construcción de vivienda} protegida en el régimen de enajenación de los patrimonios públicos de suelo

Los terrenos y edificaciones que conforman los patrimonios públicos del suelo no se desvinculan de la afectación que supone su incorporación a dicho patrimonio, de manera que, llegado el caso, el adquirente de terrenos no podrá disponer de los bienes adquiridos de la forma que tenga por conveniente. Aunque no exista planeamiento urbanístico preciso, las limitaciones de usos que en cada caso establezca la legislación urbanística se impondrán siempre.

A tales efectos, la legislación española contempla expresamente la afectación de los terrenos a la construcción de vivienda sujeta a regímenes de protección en el supuesto de cesiones gratuitas o por precio fijado a cualesquiera de las Administraciones territoriales o a entidades o empresas públicas de éstas, a entidades cooperativas, y a entidades de carácter benéfico o social sin ánimo de lucro. Más allá de lo señalado, algunas Comunidades Autónomas, como Andalucía, Castilla-La Mancha, Cataluña, Galicia o Principado de Asturias, han reforzado la afectación de los patrimonios públicos del suelo a la construcción de vivienda protegida también en la regulación de los actos de disposición mediante enajenación a terceros que no constituyan entes públicos, entidades cooperativas o 
entidades de carácter benéfico o social sin ánimo de lucro, con alcance y formulaciones diferentes en cada una de ellas.

Así, sólo en la Comunidad Autónoma de Castilla-La Mancha, la afectación de los bienes enajenados, cualquiera que éstos sean, se impone, en términos absolutos, a la construcción de vivienda protegida, privando a las Administraciones titulares de toda discrecionalidad al respecto, limitando así cualquier desviación hacia fines más lucrativos. Igualmente, en Cataluña, se impone obligatoriamente la afectación de los terrenos a la construcción de vivienda protegida, pero sólo en el supuesto de que se trate de suelo correspondiente al porcentaje de aprovechamiento urbanístico de cesión obligatoria y gratuita, tanto en suelo urbano como en suelo urbanizable. En Galicia, la legislación urbanística se ha limitado a priorizar la afectación de los bienes integrantes de los patrimonios públicos a la construcción de vivienda protegida. Esto es, la afectación se contempla a ese nivel, sin llegar a imponerse, y a condición de que exista demanda de tales viviendas, en cuyo caso "al menos, el 50 por 100 de los bienes y derechos obtenidos con cargo al 10 por 100 de cesión obligatoria serán destinados preferentemente a cubrir dicha necesidad"10, lo que ciertamente posibilita desviaciones hacia otros fines que puedan resultar más rentables a la Administración titular, sobre todo si tenemos en cuenta que en esta Comunidad Autónoma, a diferencia de lo que sucede en el resto, se permite que las enajenaciones se lleven a cabo mediante "Ios correspondientes instrumentos de equidistribución o bien mediante convenio", prescindiendo de las exigencias procedimentales que se derivan de la naturaleza administrativa de los contratos de enajenación de terrenos integrantes del patrimonio público del suelo ${ }^{11}$.

\footnotetext{
${ }^{10}$ Art. 177.3 de la Ley 9/2002, de 30 de diciembre, de Ordenación Urbanística y Protección del Medio Rural de Galicia.

${ }^{11}$ La jurisprudencia contencioso-administrativa ha afirmado la naturaleza administrativa del contrato de enajenación de terrenos del Patrimonio Municipal del suelo (STS 21 de diciembre de 1993, Ar. 9839). A tenor del artículo 112 del RBEL, las enajenaciones se regirán en cuanto a su preparación y adjudicación por la normativa reguladora de la contratación de las corporaciones locales, en la actualidad, el TR de Contratos de las Administraciones Públicas de 2001.
} 
Por lo que se refiere al Principado de Asturias, la afectación no sólo se prioriza, sino que se impone, pero en términos relativos también, "siempre que el valor del aprovechamiento que tenga atribuido el terreno lo haga viable"12.

\section{La afectación a la construcción de vivienda protegida en el régimen de las reservas de suelo}

A través del planeamiento urbanístico general es posible establecer reservas de suelo de posible adquisición por las Administraciones urbanísticas para incorporarlos a los patrimonios públicos de suelo, sujetando dichos terrenos al régimen de usos y gestión que la legislación predisponga para los propios patrimonios de suelo. Esta posibilidad, introducida ya en su momento por el legislador estatal, se ha mantenido en todas las leyes urbanísticas autonómicas.

A las reservas de terrenos de posible adquisición para constituir o ampliar patrimonios públicos de suelo se las dota de un régimen propio, con independencia del establecido para el resto de los terrenos que formen parte de los patrimonios públicos de suelo, en las Comunidades Autónomas de Cataluña, País Vasco y Principado de Asturias, predisponiendo un modelo diferente en cada caso.

En Cataluña, por ejemplo, es posible la adquisición por expropiación de los terrenos objeto de reserva, que debe llevarse a cabo con la tramitación previa de un proyecto de delimitación, ajustado al procedimiento establecido para aprobar los planes de ordenación urbanística municipal. En dicho proyecto de delimitación deberá respetarse un porcentaje

\footnotetext{
${ }^{12}$ Art. 164.1.a) de la Ley 3/2002, de Régimen del Suelo y Ordenación Urbanística del Principado de Asturias. La fijación del valor de los terrenos integrantes de los patrimonios públicos del suelo con arreglo a los criterios establecidos en la legislación urbanística estatal debe tenerse en cuenta, necesariamente, a efectos del destino concreto a que deban resultar afectados los terrenos que sean objeto de cesión onerosa. Conforme al art. 164.1.a) citado, el valor del aprovechamiento que tenga atribuido el terreno es condicionante de la afectación de los terrenos a la construcción de viviendas sujetas a algún régimen de protección pública, siempre que el citado valor "lo haga viable". Sólo en este caso, el valor de los terrenos será necesariamente y en todo caso su valor urbanístico, y no otro. Ello quiere decir también que sólo en este caso se ha impuesto de manera absoluta por el legislador asturiano, como criterio determinante a efectos de afectación de los terrenos, el valor monetarizado del aprovechamiento que permita el planeamiento (aprovechamiento real), y no del susceptible de apropiación.
} 
de reserva para vivienda de protección: "con independencia de las viviendas de protección pública destinadas a reposición, debe hacerse la reserva de un mínimo del 25 por 100 del total de viviendas previstas en las delimitaciones para nuevas ofertas de viviendas de protección pública". Igualmente, en los terrenos efectivamente expropiados en ejecución de los proyectos de delimitación, se condiciona la actuación urbanística, cuando se trate de suelo urbanizable no delimitado o suelo no urbanizable no sometido a protección especial, a que se "constate el compromiso de la Administración expropiante de poner a disposición del mercado inmobiliario, en régimen de protección pública, todas las viviendas resultantes, mediante alquiler, derecho de superficie u otras fórmulas admitidas en Derecho que conlleven la titularidad pública del suelo, como mínimo, a lo largo de treinta años desde la primera utilización de las viviendas".

El modelo establecido en el País Vasco parte de la consideración de que la adquisición de terrenos $\mathrm{u}$ otros bienes inmuebles por la Administración autonómica o por los órganos forales de sus territorios históricos podrá realizarse mediante cualesquiera de las fórmulas que la legislación posibilita, pudiendo actuar expresamente mediante expropiación cuando la adquisición lo sea a los fines de la construcción de viviendas de protección oficial. Para que tales terrenos puedan desarrollarse deberán contar con la clasificación, calificación y ordenación adecuadas y disponer de los debidos instrumentos de urbanización y gestión, de acuerdo con la legislación urbanística vigente. A tales efectos, y como regla general, la formulación y tramitación de los instrumentos de planeamiento, urbanización y gestión precisos corresponderá a la Administración autonómica y la de los territorios históricos, siempre que así se lo encomienden los Ayuntamientos de los municipios afectados, sin perjuicio de los acuerdos que, en el marco de sus competencias éstos deban adoptar. Solo excepcionalmente, cuando razones de interés público debidamente justificadas así lo requieran, el Gobierno Vasco también podrá autorizar a la Administración autonómica y la de los territorios históricos para que formulen y tramiten dichos instrumentos. El desarrollo de las actuaciones promovidas deberá comunicarse, en cualquier caso, al Ayuntamiento correspondiente, para que pueda manifestar su conformidad o disconformidad. En última instancia, será el Gobierno Vasco quien podrá autorizar su inmediata ejecución si el Ayuntamiento no manifiesta expresamente su conformidad. 
Más allá de su posible vinculación a la constitución o ampliación de los patrimonios públicos de suelo y a su régimen propio la obtención de reservas para actuaciones de iniciativa pública que tengan por finalidad, entre otras posibles, el fomento de la vivienda sujeta a cualesquiera regímenes de protección, se encuentra sujeto igualmente a una regulación específica en la legislación urbanística del Principado de Asturias. La Ley 2/1991, de 11 de marzo, de Reserva de Suelo y Actuaciones Urbanísticas Concertadas configuró tempranamente un marco de intervención de la Administración autonómica para actuaciones con diversos destinos sociales, entre ellos, la atención a la necesidad de vivienda protegida, de conformidad con el planeamiento urbanístico general: A tales efectos predisponía diferentes instrumentos, entre ellos, la posibilidad de que se conformara un patrimonio regional de suelo mediante la posibilidad de acudir a la expropiación a fin de constituir una reserva de suelo, aunque sin dotarlo del régimen que le es propio a estos patrimonios públicos, en particular, sin que quedara caracterizado como un patrimonio separado, aunque sí sujeto a un régimen específico que suponía una limitación de destinos y unas especialidades procedimentales en cuanto a su gestión ${ }^{13}$. En su redacción inicial, esta posibilidad de constitución de reservas quedaba limitada a los terrenos incluidos en las áreas previamente delimitadas a efectos de ejercicio de los derechos de tanteo y retracto. Otros de los instrumentos predispuestos por dicha normativa fue la declaración de actuación prioritaria. No obstante, en la normativa asturiana vigente juegan como técnicas independientes entre sí las referidas a la delimitación de áreas de tanteo y retracto sobre

\footnotetext{
${ }^{13}$ El Texto Refundido vigente determina ya la plena configuración del patrimonio regional de suelo como institución de la misma naturaleza y significación que los patrimonios municipales. En lo que se refiere a los bienes integrantes, la regulación del art. 162 ha ampliado considerablemente su composición, de tal manera que ya no sólo estará integrado por los terrenos y edificaciones, tanto precedentes del ejercicio de los derechos de tanteo y retracto, u obtenidos por expropiación para la constitución de reservas de suelo, en las áreas delimitadas a tales efectos, sino que del mismo pasan a formar parte, junto a los que se acaban de citar: Los terrenos y edificaciones que se obtengan, en general, por el ejercicio por la Administración autonómica de la actividad urbanística y de ordenación del territorio, o los que se adquieran con la expresa finalidad de incorporarlos al mismo; los aprovechamientos urbanísticos que correspondan al Principado de Asturias en los supuestos en que actúe como Administración urbanística; y los derechos económicos procedentes de las actuaciones que tengan por objeto bienes de dicho patrimonio regional. Del art. 162.2 se deriva también la atribución a este patrimonio la condición de patrimonio separado. Esto es, la Ley quiere que funcione como un conjunto de bienes afectos al cumplimiento de unos fines determinados, fines que no son cualesquiera de los que el Principado de Asturias ha de perseguir según las competencias de que disponga, sino el específico y concreto de "facilitar la ejecución de los instrumentos de ordenación del territorio, obtener reservas de suelo para actuaciones de interés regional, y contribuir a la consecución de los fines de los demás patrimonios públicos de suelo", según señala el art. 161.1.
} 
suelo y edificaciones, la declaración de reservas regionales de suelo, y la declaración de las que han pasado a denominarse actuaciones urbanísticas concertadas. Sistematizando la regulación ahora vigente, la delimitación de áreas de tanteo y retracto sobre suelo y edificaciones, a efectuar tanto por el Principado de Asturias como por los Ayuntamientos, y la declaración de reservas regionales de suelo, que compete obviamente declarar sólo al Principado de Asturias, deben ser identificadas claramente como instrumentos de intervención en el mercado del suelo. A su servicio, la declaración de actuaciones urbanísticas concertadas pasa a estar considerada, en exclusividad, como técnica a través de la cual ordenar y gestionar urbanísticamente las áreas de reserva o de titularidad pública de suelo en supuestos excepcionales, cuando se entienda que concurran especiales circunstancias urbanísticas deficitarias que requieran una intervención perentoria. La declaración formal posibilitará la tramitación inmediata por la propia Comunidad Autónoma del instrumento de planeamiento urbanístico que fuere exigible en función de la situación de los terrenos en que se actúe, que bien podrá ser un Plan Parcial o un Plan Especial, acomodado en sus determinaciones a reglas propias. Entre los usos específicos que posibilitan una intervención de este tipo se encuentran los residenciales, y dentro de ellos, se priorizan todas las modalidades de viviendas sujetas a algún régimen de protección pública, incluidas por tanto, la construcción tanto en régimen de venta como en régimen de alquiler.

\section{Los estándares urbanísticos de vivienda protegida}

Con la finalidad de establecer criterios de fondo a observar obligatoriamente por el planeamiento urbanístico, reduciendo su ámbito de discrecionalidad para la fijación de las opciones materiales de la ordenación urbanística, en la mayoría de las Comunidades Autónomas se introdujeron estándares de vivienda protegida, que posteriormente la legislación estatal generalizó para todo el territorio español.

Como es sabido, el estándar constituye la técnica idónea para corregir, con medidas puramente legislativas, las deficiencias de gestión urbanística que puedan existir como consecuencia de la incapacidad de la Administración urbanística para imponer por sí misma 
opciones de ordenación mínimamente satisfactorias ${ }^{14}$. La finalidad básica a que responden no es otra que la reducción de la discrecionalidad de la potestad de planeamiento para ordenar la urbanización del territorio, mediante la fijación de opciones de fondo mínimas o máximas configuradoras de límites de aquella potestad.

En este caso, los estándares legales de proporción mínima de suelo destinado a vivienda protegida operan sobre la facultad específica de calificación urbanística. Esta solo será legítima y conforme a Derecho en la medida en que cumpla aquellos estándares. La legislación urbanística autonómica configura específicos estándares para cada uno de los tipos de Plan en los que considera oportuno que jueguen aquellos. De ahí que existan unos estándares aplicables en la formulación de Planes Generales y otros que lo son en la de Planes parciales, quedando excluidos el resto. La fijación del estándar lo es en relación a concretas categorías de suelo. Esto es, no actúa en forma independiente a la clasificación del suelo. El estándar consiste en la exigencia de que el instrumento de ordenación de que se trate califique suelo con destino a vivienda protegida en la proporción mínima. Ello supone que el instrumento de ordenación necesaria y obligatoriamente ha de contener una previsión del que ha de resultar de las opciones de ordenación por él establecidas. La superficie mínima de vivienda protegida, y por tanto, el cumplimiento del estándar legal, derivan lógicamente de aquella previsión. La determinación queda sujeta al cumplimiento de un contenido mínimo legal de las reservas de viviendas protegidas, por el doble procedimiento de la fijación de una proporción entre la superficie de dichas reservas y el número de viviendas o, en su caso, la cantidad de metros cuadrados de edificación residencial previstos por el Plan y, alternativamente, del señalamiento de una superficie destinada a aquellas reservas que en todo caso debe ser respetada. En el caso de los Planes Parciales, el estándar opera a escala de sector, no a nivel municipal general, con independencia de las exigidas por el Plan General.

En principio, el precepto legal, antes de concretar los términos del estándar, fija al Plan el criterio básico con arreglo al cual han de establecerse las determinaciones relativas a las reservas de suelo. Tal criterio consiste en que aquellas reservas han de ser adecuadamente proporcionadas a las necesidades colectivas. La reserva legal ha de tener un porcentaje

\footnotetext{
${ }^{14}$ Así, GARCía DE ENTERRÍA, E. y PAREJO ALFONSO, L., Lecciones de Derecho Urbanístico, Civitas, 2ae ed., 1981, pág. 185.
} 
mínimo. La forma de cómputo de la proporción exige que el Plan contenga la determinación del número total de viviendas o cantidad total de metros cuadrados de edificación residencial resultantes de la ordenación por él establecidas, pues de otra forma no sería controlable el cumplimiento del estándar legal.

La reserva de suelo resultante de la aplicación de la proporción mínima tiene, a su vez, un tope mínimo. Este del tope mínimo es el verdadero carácter de este nuevo límite y no el de una tercera alternativa del cómputo del estándar en ausencia de la determinación por el Plan del número de viviendas o cantidad de metros cuadrados. El Plan tiene que contener obligatoriamente alguna de dichas dos determinaciones en cuanto que la comprobación del cumplimiento del estándar legal ha de hacerse siempre y necesariamente a partir de una de ellas.

El art. 10 de la Ley de Suelo estatal de 2008 ha procedido a generalizar para todo el territorio español un estándar urbanístico de vivienda protegida, imponiendo a las Administraciones públicas la obligación de "destinar suelo adecuado y suficiente para usos productivos y para uso residencial, con reserva en todo caso de una parte proporcionada a vivienda sujeta a un régimen de protección pública que, al menos, permita establecer su precio máximo en venta, alquiler u otras formas de acceso a la vivienda, como el derecho de superficie o la concesión administrativa".

Esta reserva será determinada por la legislación sobre ordenación territorial y urbanística o, de conformidad con ella, por los instrumentos de ordenación y, "como mínimo, comprenderá los terrenos necesarios para realizar el $30 \%$ de la edificabilidad residencial prevista por la ordenación urbanística en el suelo que vaya a ser incluido en actuaciones de urbanización". No obstante, dicha legislación podrá también fijar o permitir excepcionalmente una reserva inferior para determinados municipios o actuaciones, siempre que, cuando se trate de actuaciones de nueva urbanización, se garantice en el instrumento de ordenación el cumplimiento íntegro de la reserva dentro de su ámbito territorial de aplicación y una distribución de su localización respetuosa con el principio de cohesión social. 


\section{Referencias bibliograficas}

AGUINAGA MARTÍNEZ, M. (2002), "El patrimonio municipal del suelo como fuente de ingresos para los Ayuntamientos", Papeles de Economía Española, 92 (2002): 23-36.

BERMEJO VERA, J. (2001), Derecho Administrativo. Parte especial, Civitas, 5a ed., Madrid.

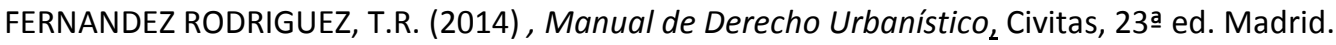

FONSECA FERRANDIS, F.E. (1995), El régimen jurídico de los patrimonios municipales del suelo, Instituto Pascual Madoz/BOE, Madrid.

GARCÍA DE ENTERRÍA, E. y PAREJO ALFONSO, L. (1981), Lecciones de Derecho Urbanístico, Civitas, 2aa ed., Madrid.

MERELO ABELA, J.M. (1996), Régimen Jurídico del Suelo y Gestión Urbanística, Editorial Praxis, Madrid.

PAREJO ALFONSO, L. (1998), "La capacidad autonómica de establecimiento de una ordenación urbanística propia en el marco de la Ley 6/1998, de 13 de abril, de Régimen del Suelo y Valoraciones", Revista de Derecho Urbanístico, 166 (1998): 12-29.

SALANOVA ALCALDE, R. (2003), "Patrimonio públicos de suelo”, en LÓPEZ RAMÓN, F. (Dir.), Estudio sistemático de la Ley Urbanística de Aragón, Cortes de Aragón, Zaragoza.

TEJEDOR BIELSA, J. (2010): “Régimen jurídico general de la vivienda protegida”, en LOPEZ RAMON, F. (Coord.) Construyendo el derecho a la vivienda, Editorial Marcial Pons, Madrid. 